\title{
LA CUESTIÓN DE LA NATURALEZA DE LOS MINISTROS DEL SANTO OFICIO PORTUGUÉS. DE LAS DISPOSICIONES LEGISLATIVAS A LA PRÁCTICA COTIDIANA
}

\author{
ANA ISABEL LÓPEZ-SALAZAR CODES \\ CIDEHUS - U. Évora*
}

RESUMEN: Durante los casi tres siglos de su existencia, entre 1536 y 1820, numerosos extranjeros sirvieron al Santo Oficio portugués. Se trató, sobre todo, de familiares, especialmente mercaderes y hombres de negocios gallegos. Pero bubo también numerosos calificadores, algunos comisarios, varios diputados y hasta un inquisidor de origen español. En realidad, los Regimentos ordenados en 1552, 1570 y 1613 nada decían sobre la naturaleza de los ministros y oficiales del tribunal. Solo en 1640, como respuesta a los constantes debates que tuvieron lugar durante la Unión Dinástica sobre la introducción de inquisidores españoles en el tribunal portugués, el Santo Oficio luso decidió ordenar el requisito de la naturaleza. No obstante, terminada la Guerra de Restauración, los extranjeros volvieron a ingresar sin problemas en la Inquisición portuguesa que, por su parte, eliminó dicha condición en las nuevas instrucciones ordenadas por el cardenal da Cunba en 1774.

Palabras Clave: Portugal. Monarquía Hispánica. Edad Moderna. Inquisición. Naturaleza.

Ana Isabel López-Salazar Codes es becaria pos-doctoral de la Fundação para a Ciência e a Tecnologia do Ministério de Ciência, Tecnologia e Ensino Superior (Portugal). Dirección para correspondencia: Centro Interdisciplinar de História, Culturas e Sociedades (CIDEHUS-U.Évora), Universidade de Évora, Palácio do Vimioso,Apartado 94, 7002-554 Évora(Portugal).Correo electrónico: ailopezsalazar@hotmail.com.

* Este trabajo se integra en el proyecto de investigación FCT/COMPETE/FEDER: FCOMP01-0124-FEDER-007360. Deseo agradecer a Bruno Lopes, Leonor Garcia y Ofelia Sequeira, becarios de dicho proyecto, su generosa ayuda. Asimismo, agradezco a la profesora Fernanda Olival sus comentarios y sugerancias. En este artículo hemos utilizado las siguientes abreviaturas: AGS (Archivo General de Simancas), ANTT (Arquivo Nacional da Torre do Tombo - Lisboa), BNE (Biblioteca Nacional de España), CG (Conselho Geral), IC (Inquisição de Coimbra), IE (Inquisição de Évora), IL (Inquisição de Lisboa) y TSO (Tribunal do Santo Ofício). 
THE PROBLEM OF THE NATIONALITY OF MINISTERS AND OFFICERS OF THE PORTUGUeSE Holy OFFICE. From LEGAL ORDERS TO THE DAILY PRACTICE

ABSTRACT: Many foreigners served the Holy Office in Portugal for its almost three centuries of existence (1536-1820). They were mainly relatives, especially Galician merchants and businessmen. However, among them we also find various "qualifiers», some commissioners and even an inquisitor of Spanish origin. Actually, the Regiments that were ordained in 1552, 1570 and 1613 did not state anything about the nationality of the Ministers and Officers of the Court. It was not until 1640, as a response to the continuous debates that took place during the Dynastic Union about the introduction of Spanish inquisitors in the Portuguese court, that the Portuguese Holy Office decided to implement the requisite of nationality. However, once the Restoration War was over, foreigners joined the Portuguese Inquisition again without problems, as it had, eliminated that requisite in the new instructions commissioned by the cardinal da Cunba in 1774.

KEY WORDS: Portugal. Hispanic Monarchy. Modern Age. Inquisition. Nationality.

\section{INTRODUCCIÓN: LA INFLUENCIA DE LA INQUISICIÓN ESPAÑOLA EN LA POR- TUGUESA}

Creado muchos años después que el tribunal español, el Santo Oficio portugués aprovechó, sin duda, la experiencia organizativa y procesal acumulada por su homólogo. Cuando se estableció la Inquisición en Portugal, en 1536, el tribunal ya contaba con casi sesenta años de antigüedad en España. Por ello, no es de extrañar que en cuestiones jurisdiccionales, institucionales, procesales e, incluso, simbólicas la Inquisición lusa debiese mucho a la española ${ }^{1}$.

En realidad, cuando don João III solicitó al papa el establecimiento de la Inquisición en Portugal, en 1531, pidió que esta fuese como la que existía en los otros reinos de la Península Ibérica. Este deseo del rey portugués de establecer en su reino un tribunal igual al que había en España queda bien patente en las instrucciones enviadas a Braz Neto, su embajador en Roma. En ellas, el monarca ordenaba:

«vos enformai dos poderes e faculdades que sam dados per os papas aos inquisidores de Castela e d'outros regnos, e com as mesmas faculdades e poderes, e mais se ser poder, pedireis a dicta inquisiçam»².

1 Bethencourt, Francisco, La Inquisición en la época moderna. España, Portugal e Italia, siglos XV-XIX, Madrid, Akal, 1994, pág. 514.

2 Instrucciones de don João III a Braz Neto, publicadas en el Corpo Diplomático Português, Lisboa, Typographia da Academia Real das Sciencias, 1862-1891, tomo II, págs. 319-322. Sobre el proceso de establecimiento del Santo Oficio en Portugal, vid. Herculano, Alexandre, História da origem e estabelecimento da Inquisição em Portugal, Lisboa, Bertrand, 1979, y MARCOCCI, Giuseppe, I custodi dell'ortodossia. Inquizione e Chiesa nel Portogallo del Cinquecento, Roma, Edizioni di Storia e Letteratura, 2004. 
De hecho, desde el punto de vista de la organización institucional, el tribunal portugués fue, en gran medida, copia del español. Es decir, se trataba de una estructura de tribunales de distrito sobre los cuales se encontraba el Consejo de la Suprema y General Inquisición, en el caso español, o el Conselho Geral do Santo Ofício, en el portugués. Evidentemente, existían diferencias entre la Suprema y el Conselho Geral, así como entre los tribunales de distrito españoles y los portugueses. No obstante, durante la Unión Dinástica, especialmente en el reinado de Felipe III, la corona intentó asimilar completamente las estructuras del Santo Oficio portugués al español ${ }^{3}$. Y, como expuso Francisco Bethencourt, a diferencia de los tribunales italianos, las Inquisiciones española y portuguesa compartieron la misma heráldica. Utilizaban las mismas armas - la cruz con el ramo de olivo y la espada - y exhibían la imagen de Santo Domingo, evocado como fundador del Santo Ofición.

Por último, desde el punto de vista procesal, la influencia del tribunal español en el portugués resulta innegable, como se puede ver claramente en un texto de tiempos de la Unión Dinástica: el Regimento o Instrucción de 1613. Este Regimento venía a sustituir al anterior de 1552, ordenado por el cardenal don Henrique. Entre ambos textos, se habían publicado en Madrid las Instrucciones del inquisidor general don Fernando de Valdés en 1561. Pues bien, en el Regimento portugués de 1613 fueron copiados capítulos íntegros de las instrucciones valdesianas sin otra modificación que no fuera la traducción del texto del castellano al portugués 5 .

Ahora bien, si, como vemos, hubo una influencia innegable del tribunal español en el luso, no podemos dejar de preguntarnos si se produjeron también intercambios de ministros entre ambas instituciones. Para responder a esta pregunta debemos partir de la cuestión de la naturaleza de los miembros del Santo Oficio y de los debates generados, especialmente durante el tiempo de los Felipes, sobre la posibilidad de introducir eclesiásticos procedentes de la Inquisición española en el tribunal portugués.

\section{LOS DEBATES SOBRE LA NATURALEZA DE LOS MINISTROS Y OFICIALES DEL SANTO OFICIO}

De acuerdo con las Ordenações Filipinas, podían considerase naturales de Portugal las personas nacidas allí cuyo padre fuese portugués y aquellos otros, también nacidos en este reino, de madre natural y padre extranjero, siempre que este hubiese vivido en Portugal diez años con casa y bienes ${ }^{6}$. Por lo tanto,

3 LÓPEZ-SAlazAR Codes, Ana Isabel, Inquisición portuguesa y Monarquía Hispánica en tiempos del perdón general de 1605, Lisboa, Edições Colibri \& CIDEHUS - U. Évora, 2010, cap. 3.

4 BethenCOURT, Francisco, La Inquisición en la época moderna, pág. 102.

5 LÓPEZ-SAlaZAR CODES, Ana Isabel, Inquisición portuguesa, pág. 205.

6 Codigo Philippino ou Ordenações e Leis do Reino de Portugal, liv. II, título LV: «Das pessoas que devem ser havidas por naturaes destes Reinos». 
era esta una definición más restringida que la que imperaba en la Castilla del momento, donde podía considerarse natural a quien residiese de forma prolongada en el reino ${ }^{7}$.

En los primeros años de funcionamiento del tribunal portugués, hubo algunos inquisidores y diputados del Conselho Geral procedentes de los otros reinos de la Península Ibérica. Así, Pedro Álvarez de Paredes, inquisidor del tribunal de Évora, había sido inquisidor de Llerena antes de ingresar en el Santo Oficio luso $^{8}$. Y fray Jerónimo de Padilla, dominico castellano que entró en Portugal en 1538 como visitador y reformador de los conventos de su orden, formó parte del primitivo Conselho Geral que asistía al cardenal don Henrique?

Por lo tanto, como vemos, durante el período en que el infante don Henrique desempeñó el cargo de inquisidor general, la existencia de ministros del Santo Ofício originarios de otros territorios de la Península Ibérica no generó ningún tipo de problema. Además, resulta bastante lógico que, en los primeros años de actividad del tribunal portugués, el inquisidor general decidiese recurrir a personas que ya contaban con experiencia en el enjuiciamiento de los delitos de fe y en el modo de proceder inquisitorial, como eran los españoles antes citados. Pero lo que durante el siglo XVI no ocasionó conflictos, en la centuria siguiente, coincidiendo con el reinado del último de los Felipes, provocará debates en la corte y obligará al Santo Oficio portugués a legislar sobre la cuestión de la naturaleza de sus ministros y oficiales.

El debate sobre la introducción de ministros españoles en el tribunal luso reapareció, de forma recurrente, durante todo el tiempo de la Unión Ibérica. Como es sabido, en las Cortes de Tomar, reunidas en 1581, Felipe II se comprometió a respetar el particularismo de Portugal en el seno de la Monarquía Hispánica. Así, el reino continuaría manteniendo sus instituciones y los oficios y beneficios serían desempeñados solo por portugueses. De hecho, en las llamadas mercedes de Almeirim, presentadas por el embajador español duque de Osuna a las Cortes portuguesas en marzo de 1580, es decir, poco después de la muerte del rey don Henrique, se especificaba que el oficio de inquisidor general sería desempeñado siempre por un portugués. No obstante -y dejando aparte el caso específico del cargo de inquisidor general — durante toda la Unión Dinástica se pensó en introducir españoles en el Santo Oficio luso.

En realidad, los Regimentos de 1552, ordenado por el cardenal-infante don Henrique, y de 1613, del inquisidor general don Pedro de Castilho, así como el Regimento del Conselho Geral de 1570 nada decían sobre la naturaleza de los ministros del tribunal, pues no era necesario. En estos textos, las cualidades re-

\footnotetext{
7 Herzog, Tamar, Vecinos y extranjeros. Hacerse español en la Edad Moderna, Barcelona, Alianza Editorial, 2006, pág. 114.

8 MAteus, Susana, "Álvarez de Paredes, Pedro», en: ProsPeri, Adriano, Diccionario storico sull'Inquisizione, Pisa, Edizione della Normale, 2010, vol. 1.

9 En 1540, fray Jerónimo de Padilla fue elegido provincial de Portugal y murió en Aveiro en 1544.
} 
queridas para ejercer el oficio de inquisidor eran de carácter moral e intelectual. Es decir, tenían que ser letrados, honestos y prudentes. Pero, en ningún caso, ni siquiera en el de los diputados del Conselho, se especificaba que debían ser naturales de Portugal. Quizás por ello, la posibilidad de introducir en Portugal inquisidores del Santo Oficio español, esto es, oriundos de las coronas de Castilla y Aragón, fue una cuestión abierta y debatida durante toda la Unión Ibérica.

Así, antes incluso de las Cortes de Tomar, ya encontramos una propuesta de este tipo. En 1580 don Diego de Torquemada, obispo de Tuy, escribía a Felipe II sobre la situación de Portugal. Torquemada proponía medios radicales para fortalecer el poder real, como la imposición de una única ley en todos los reinos de la península ibérica. En el aspecto concreto que ahora nos interesa, el obispo de Tuy recomendaba que se uniesen las dos inquisiciones de la Monarquía Hispánica, que se nombrase un único inquisidor general y que los inquisidores no tuviesen que cumplir con la obligación de la naturaleza. Así, según este obispo, era conveniente:

«que los ynquisidores de los districtos puedan ser en Portogal castellanos y de otras provincias de Hespaña como en los Reynos de Aragón porque por este medio se allanaría mucho en Portugal»10.

Evidentemente, este arbitrio no se puso en práctica, pero reapareció algunos años más tarde, a finales del reinado de Felipe II, debido a las quejas presentadas a Clemente VIII, en Roma, por los conversos Duarte Pinto y Jerónimo Duarte, fugitivos del tribunal de Évora. A raíz de las críticas de estos conversos al modo de proceder del tribunal portugués, el auditor de la Rota Francisco Peña propuso a Felipe II que, para acabar con los abusos judiciales de la Inquisición portuguesa, se ordenase que, en cada tribunal de distrito, uno de los inquisidores fuese castellano, catalán, valenciano o aragonés ${ }^{11}$.

Esta propuesta volvió a aparecer, una vez más, en los primeros años del reinado de Felipe IV, como consecuencia, de nuevo, de las críticas de los cristãosnovos al procedimiento inquisitorial. Se pensó entonces en la posibilidad de introducir inquisidores de España en el tribunal portugués, pero se desechó este medio porque se consideró que suponía una afrenta no solo a la Inquisición lusa sino a todo el reino. Interesante, no obstante, es el parecer de un tal Fernando Lorenzo, opuesto al envío de inquisidores españoles a Portugal y que, además, cuestionaba la jurisdicción del rey para intervenir en los asuntos inquisitoriales. Este Fernando Lorenzo consideraba que:

10 AGS, Estado Portugal, leg. 412, fol. 61: Carta de don Diego de Torquemada, obispo de Tuy, a Felipe II (1580). Sobre las propuestas de este prelado, vid. BouZA ÁlVAREZ, Fernando Jesús, Portugal en la Monarquía Hispánica (1580-1640): Felipe II, las cortes de Tomar y la génesis del Portugal católico, tesis doctoral, Madrid, UCM, 1986, págs. 229-230.

11 LÓPEZ-Salazar CODES, Ana Isabel, Inquisición y política. El gobierno del Santo Oficio en el Portugal de los Austrias, Lisboa, CEHR, 2011, pág. 338. 
«haçer inquisidores castellanos no es contra los previlegios del Reino por ser la materia mere ecclesiastica y de la jurisdicion del Summo Pontifice cuya potestad no puede lemitarse por leyes reales»12.

Ahora bien, aunque se tratase de una cuestión eclesiástica y aunque las instrucciones de la Inquisición portuguesa no ordenasen la naturaleza de sus ministros, lo cierto es que, conforme avanzó la Unión Dinástica, cada vez más se fue dando por supuesto que los inquisidores y ministros del Santo Oficio debían ser naturales del reino. Este requisito apareció ya claramente en un memorial de 1623 en el que se criticaba, de forma general, el gobierno del Santo Oficio por parte del inquisidor general don Fernão Martins Mascarenhas y el comportamiento y cualidades de los ministros del tribunal por él nombrados. El autor de este memorial tildaba a los ministros escogidos por Mascarenhas de conversos, sodomitas o borrachos. Pero, además, consideraba que dos de ellos - Diego de Salazar, diputado del tribunal de Évora, y Bartolomé de Monteagudo, notario de la Inquisición de Lisboa- no podían integrar del Santo Oficio porque eran extranjeros ${ }^{13}$.

El hecho de que ahora, en 1623, se acusase de extranjero a una persona como Diego de Salazar nos permite comprobar cómo había evolucionado la situación desde inicios de la Unión Dinástica, cuando entró a servir en el tribunal portugués don Alonso Coloma. Tanto uno como otro eran hijos de un extranjero y de una portuguesa. Don Alonso Coloma era hijo del conde de Elda, estado del reino de Valencia, y de la portuguesa doña Isabel de Sá, natural de Évora. Había nacido en Valencia y había estudiado en Alcalá y en Salamanca, donde perteneció al colegio mayor de Cuenca. Probablemente llegó a Portugal con el duque de Gandía, don Carlos de Borja Aragón y Castro. En septiembre de 1583, el Conselbo Geral aprobaba su información de limpieza de sangre y don Alonso entraba a servir en el tribunal de Lisboa como diputado ${ }^{14}$. Unos cuarenta años más tarde, ingresaba en el Santo Oficio, también como diputado, Diego de Salazar. Nacido muy probablemente en Portugal, era hijo del

\footnotetext{
12 ANTT, TSO, CG, maço 24, n. ${ }^{\circ}$ 11: Parecer de don Fernando Lorenzo del 4 de marzo de 1628.

13 «Bertholome de Monteagudo de veinte y quatro años estranjero hijo de un françes y nieto de un christiano nuebo que se avia acoxido a Françia por no lo prenderen en Portugal y su madre del dicho notario castellana natural de Ayamonte y se le no hiçieron informaçiones y no podiendo tener officio en el dicho Reyno por ser contra las leyes del por no ser natural del dicho Reyno de Portugal el dicho notario [...] Diego de Salaçar estrangero contra las leyes del Reyno y sin informaçiones en los lugares donde eran naturales sus padres y aguelos paternos amançebado sin ser graduado y de veinte y cinco años de edad». BNE, mss. 718, fols. 359r-372v. Sobre la posible autoría de este texto, vid. Pulido SERRANO, Juan Ignacio, Injurias a Cristo. Religión, política y antijudaísmo en el siglo XVII, Madrid, Instituto Internacional de Estudios Sefardíes y Andalusíes Universidad de Alcalá, 2002, págs. 86-87. LÓPEZ-SALAZAR CODES, Ana Isabel, Inquisición y política, págs. 63-66.

14 ANTT, TSO, CG, Habilitações, maço 1, dilig. 29 (Alonso Coloma). Cf. ANTT, TSO, IL, liv. 104, fls. 46-47.
} 
capitán Diego de Salazar, que entró en el reino con los ejércitos del duque de Alba y que casó con una portuguesa cuyo nombre desconocemos ${ }^{15}$. Por lo tanto, como vemos, su situación era semejante a la de don Alonso Coloma. Sin embargo, en 1623 había quien podía acusar a Diego de Salazar de no ser natural del reino.

El memorial contra don Fernão Martins Mascarenhas tuvo repercusiones a largo plazo en la carrera de ambos ministros, Salazar y Monteagudo, y en la historia del tribunal. Veamos qué pasó con Bartolomé de Monteagudo. Era este natural de Ayamonte, en Andalucía, hijo de Andrés Martín, un alemán, probablemente comerciante, que murió en Indias, y de Francisca de Monteagudo, que pertenecía a una familia de mercaderes levantinos asentados en Ayamonte $^{16}$. Cuando tenía 14 o 15 años, en torno a 1612, Bartolomé se trasladó a la cercana ciudad de Faro para servir al entonces obispo del Algarve don Fernão Martins Mascarenhas. En 1616, este fue nombrado inquisidor general de Portugal y al año siguiente Bartolomé de Monteagudo ingresaba en el Santo Oficio. De acuerdo con el memorial antes citado, Monteagudo habría recibido el cargo en el tribunal sin que se hubiesen realizado antes las pruebas de limpieza de sangre. O bien se equivocó el autor o bien mintió deliberadamente, porque sí fue hecha la información en Ayamonte y aprobada por el Conselbo Geral. A pesar de estas pruebas, en el citado memorial de 1623 se acusaba a Monteagudo de descendiente de conversos por parte de su padre. Quizás por ello, cuando murió su protector, el inquisidor general Mascarenhas, el Santo Oficio ordenó realizar nuevas informaciones en Ayamonte. $Y$ estas fueron aprobadas, cosa poco común, por el Conselbo Geral ante el nuevo inquisidor general don Francisco de Castro. Probablemente intentaba taparse así la mancha que el memorial presentado ante Felipe IV había lanzado sobre el ministro del Santo Oficio. Es decir, esta segunda información se hacía por haber sido acusado de converso, no porque fuera extranjero ${ }^{17}$. De hecho, poco después Monteagudo fue nombrado inquisidor del tribunal de Évora y permaneció en Portugal, al servicio del Santo Oficio, durante la guerra de Restauración.

El proceso de imposición de la naturaleza como requisito para los ministros y oficiales del Santo Oficio culminó en el Regimento de 1640, ordenado por el

15 ANTT, TSO, CG, Habilitações, maço 2, doc. 51 (Diego de Salazar). La diligencia está incompleta, pues solo consta de los interrogatorios realizados por la Inquisición de Toledo referidos al padre de Diego de Salazar. Por el contrario, no aparecen las indagaciones realizadas en Portugal sobre su limpieza de sangre por vía materna.

16 El iberismo del nombre de Andrés Martín puede deberse a que adecuase su apellido original germánico a la fonética española o a que, como sugiere el memorial de 1623 , fuese descendiente de portugueses.

17 En la requisitoria enviada por la Inquisición de Lisboa a la de Sevilla se justificaba este nuevo pedido de información de la siguiente forma: «como não hé natural deste Reino, se não teve tegora a certeza (que convém) da limpeza de seu sangue». ANTT, TSO, CG, Habilitações, maço 1, doc. 14 (Bartolomeu de Monteagudo). 
inquisidor general don Francisco de Castro y que, curiosamente, entró en vigor el 1 de diciembre de dicho año, el mismo día en que un grupo de nobles proclamaba la independencia de Portugal. En esta instrucción, en el apartado dedicado a las cualidades de los ministros del tribunal, aparecía, en primer lugar y antes de las consabidas de limpieza de sangre y sin infamia, la de ser oriundo de Portugal.

Evidentemente, esta disposición no hacía sino retomar las leyes del reino y los capítulos de las cortes de Tomar de 1581 que prohibían la concesión de oficios y beneficios a los no naturales. Ahora bien, establecer la distinción entre naturales y extranjeros no era fácil y, por ello, el Santo Oficio decidió seguir los mismos criterios que establecían las Ordenações Filipinas. Es decir, según el inquisidor João Álvares Soares, que escribió un comentario al Regimento de 1640, debían considerarse naturales los nacidos en Portugal hijos de padres portugueses, los nacidos en el reino hijos de padres extranjeros que viviesen en él o los nacidos fuera de las fronteras hijos de portugueses ${ }^{18}$. Junto a las Ordenações, otras fuentes jurídicas de la nueva disposición del Regimento relativa a la naturaleza eran la Practica Lusitana de Manuel Mendes de Castro, las Decisiones de Pereira y el De Patronatibus de Jorge de Cabedo ${ }^{19}$. Así, Cabedo mantenía que los extranjeros no podían poseer beneficios eclesiásticos en Portugal e invocaba en su auxilio una provisión de don Manuel del año $1512^{20}$. Y, en el título dedicado a las cualidades que debía reunir cualquier juez, Manuel Mendes de Castro señalaba que la primera de ellas debía ser la naturaleza ${ }^{21}$.

En realidad, la obligación de naturaleza que aparece en el Regimento de 1640 parece tratarse de un requisito momentáneo y de circunstancia, motivado por el contexto específico en que se encontraba Portugal, integrado en la Monarquía Hispánica, y por los constantes debates sobre la introducción de ministros españoles en el tribunal luso. Ello explica que, cuando la situación política cambió, mudó también la percepción que el Santo Oficio tenía sobre la cuestión de la naturaleza de sus ministros. Así, en unos comentarios al Regimento de 1640 elaborados a principios del siglo XVIII y dirigidos al inquisidor general don Nuno da Cunha, el autor -Francisco Carneiro de Figueiroa - afirmaba que, a pesar de lo dispuesto por las leyes seculares, los inquisidores generales podían nombrar a extranjeros para desempeñar cargos en el Santo Oficio ${ }^{22}$. De

18 ANTT, TSO, CG, liv. 123: Tribunale perfectum sive commentaria ad Regimen Sancti Officii regni Portugaliae. Opere et labore Joannis Alvares Soares Ulyssiponensis Inquisitoris, n. ${ }^{\circ}$ 53-58.

19 ANTT, TSO, CG, liv. 135: Cottas ao Regimento do S. Officio trasladadas do Regimento que foy do Sr. Inquisidor D. Alexandre da Silva do Conselho Geral e Bispo de Elvas.

20 CABEDo, Jorge de, De patronatibus ecclesiarum regia coronae Regni Lusitaniae, Lisboa, Gregorio Rodrigues, 1602, cap. 29.

21 Castro, Manuel Mendes de, Practica Lusitana omnibus utroque foro versantibus utilíssima $\mathcal{E}$ necessária, Lisboa, Gregorio Rodrigues, 1619, libro 1, cap. 2, título 9.

22 «Poterit tamen inquisitor generalis exteros assumere ad officia Sancti Inquisitionis non obstantibus legibus secularibus illos excludentibus ab omnibus officiis publicis», ANTT, TSO, CG, liv. 345: Anotationes ad Regimen Sancti Officii Inquisitionis Regnorum Portugaliae. Tomus 1. 
hecho, en las nuevas reglas dictadas por el cardenal da Cunha en 1720 sobre el modo de llevar a cabo las pruebas de limpieza de sangre no se refiería en ningún caso la obligación de la naturaleza ${ }^{23}$. Y este requisito desapareció en el Regimento ordenado por el cardenal da Cunha en 1774. Es decir, de las cinco instrucciones del tribunal $(1552,1570,1613,1640$ y 1774), solo apareció, precisamente, en la de 1640.

\section{EXTRANJEROS AL SERVICIO DEL SANTO OFICIO PORTUGUÉS}

Independientemente de lo que dispusiesen las normas, durante toda la historia del Santo Oficio ingresaron en el tribunal portugués numerosos extranje$\operatorname{ros}^{24}$. En 1764, el padre irlandés João Currim, que llevaba más de diez años intentando ser nombrado comisario del Santo Oficio, consideraba que la demora se debía, probablemente, a que algunos de sus feligreses habrían declarado en su contra y no a ser extranjero. Como él dijo:

«Este o motivo porque se julga embaraçado, poes não considera outro nem se persuade que o seja o não ser o suplicante oriundo deste Reyno, por ser timbre e grandeza delle o honrar em todo tempo aos estrangeiros que procurão alistarse debaixo das bandeiras de tão clementissimos e fidelissimos monarcas» ${ }^{25}$.

No obstante, sí es cierto que la inmensa mayoría de los no naturales que integraron el tribunal ingresaron en él antes de la publicación del Regimento de 1640 - que establecía, como hemos dicho, el requisito de la naturaleza- o a partir de la década de 1670, es decir, después ya de la Guerra de Restauración. Así, durante la guerra, solo conocemos los casos de tres familiares extranjeros: el español Francisco Díaz de Barros y el genovés Francisco Della Chiesa, nombrados familiares en 1642, y el francés Francisco André, que obtuvo la familiatura en $1651^{26}$. El resto entraron en el Santo Oficio ya después de firmada la paz con la Monarquía Hispánica en 1668.

Sin duda, el período en el que la Inquisición portuguesa contó con mayor número de extranjeros fue el siglo XVIII. Ello se debe a varios motivos. En

23 ANTT, TSO, CG, liv. 35, fol. 139: Ordem de Sua Excelência a respeito de habilitandos (12 de julio de 1720).

24 En este texto, hemos decidido mantener los nombres propios en portugués actual y escribir correctamente en español, francés o inglés los apellidos. Una primera aproximación a los ministros y oficiales extranjeros del Santo Oficio portugués fue realizada por BRAGA, Paulo Drumond, «Estrangeiros ao serviço da Inquisição portuguesa», en: Estudos em bomenagem a João Francisco Marques, Porto, Faculdade de Letras da Universidade do Porto, 2001, vol. I, págs. 253-260.

25 ANTT, TSO, CG, Habilitações, mç. 129, doc. 2002 (João Currim), fol. 21r: Petición del pretendiente (sin fecha).

26 ANTT, TSO, CG, Habilitações, mç. 6, doc. 256 (Francisco Dias de Bairros); mç. 7, doc. 290 (Francisco André). ANTT, TSO, IL, liv. 105, fols. 66r-66v. 
primer y principal lugar, la mayoría de los extranjeros que formaban parte del Tribunal de la Fe eran familiares y el Setecientos fue la época de mayor crecimiento del número de familiaturas ${ }^{27}$. Además, en este siglo, la mayor parte de los familiares pasaron a ser mercaderes y hombres de negocios, entre los cuales había un porcentaje considerable de no naturales. Por ello, durante el XVIII ingresaron en el Santo Oficio numerosos familiares nacidos fuera de Portugal y, lo que es más interesantes aún, sin antepasados lusos. Es el caso, por ejemplo, del ingeniero Pedro Vicente Vidal, natural de Valencia y cuyos padres y abuelos eran levantinos; del médico Martín Nicolás Gil, oriundo de Galicia, y del también médico Mateo Juver, natural de Tortosa, cuyos ascendientes eran todos catalanes. En 1734, 1746 y 1754, respectivamente, Vidal, Gil y Juver obtuvieron las cartas de familiar del Santo Oficio portugués ${ }^{28}$. Y si Pedro Esteve y Oriol, originario de Tortosa, no consiguió la familiatura no fue por no ser portugués, sino porque tenía una antepasada morisca y, por ese motivo, dos parientes suyos no habían superado las pruebas de limpieza de sangre realizadas por el tribunal de Valencia en el siglo XVII ${ }^{29}$. Tampoco el problema que tuvo José Bourgarel para ser familiar del Santo Oficio se debió a que era natural de Marsella, hijo y nieto de franceses, sino a la falta de información sobre sus antepasados y los de su mujer ${ }^{30}$.

Además de estos familiares, también hubo algunos — pocos, es ciertocomisarios del Santo Oficio extranjeros. En concreto, hemos conseguido encontrar tres españoles y dos irlandeses. En 1611, ingresaba en el Santo Oficio, como comisario en Río de Janeiro, Juan de Membrive, natural de Budía, en el obispado de Sigüenza ${ }^{31}$. Los otros dos españoles que desempeñaron el oficio de comisarios del tribunal portugués vivieron ya a finales del siglo XVII y en el XVIII, eran extremeños y, además, tenían sangre lusa. Así, el abuelo de Pedro Vivas de Carvajo, natural de Valencia de Alcántara (Cáceres), era portugués, de Castelo da Vide. Y Francisco Tudela de Castilho y Costa, nacido en Alburquerque (Badajoz), era hijo de un portugués, natural de Abruñosa, y de una castella-

27 Según los datos proporcionados por José Veiga Torres, hasta el último cuarto del siglo XVII el Santo Oficio concedía unas 330 familiaturas por decenio. Entre 1720 y 1770 ese número ascendió hasta las 1.730. ToRRES, José Veiga, «Da repressão religiosa para a promoção social. A Inquisição como instância legitimadora da promoção social da burguesia mercantil», Revista Crítica de Ciências Sociais, 40 (1994), pág. 130.

28 ANTT, TSO, CG, Habilitações, mç. 22, doc. 438 (Pedro Vicente Vidal); mç. 4, doc. 85 (Martinho Nicolau Gil); mç. 4, doc. 57 (Mateus Juver).

29 ANTT, TSO, CG, Habilitações, mç. 27, docs. 509-510 (Pedro Esteve y Oriol).

30 «... ele tem boa capacidade para a occupação de familiar do Santo Ofício, que pertende. Como porem se não prove, como he necessário, a ascendencia do pertendente e de sua mulher a respeito de seus avós paternos e maternos e dos paternos da dita sua mulher [...] me parece que não está em termos de se difirir a sua pertenção». ANTT, TSO, CG, liv. 35, fol. 39.

31 Juan de Membrive había viajado a las Indias en compañía de fray García de Santa María Mendoza y Zúñiga, O.S.H., nombrado arzobispo de México en 1600. 
$n^{32}$. Vivas de Carvajo y Tudela de Castilho fueron nombrados comisarios de Abrantes y de Santo Estévão (Guarda) en 1684 y 1755, respectivamente ${ }^{33}$.

Como señaló Domínguez Ortiz hace años, los irlandeses que emigraban a la Península Ibérica eran o militares o religiosos ${ }^{34}$. Por ello, no es de extrañar que algunos de estos últimos terminaran ingresando en el Santo Oficio. Irlandeses eran los comisarios Hugo Maguire, nombrado en 1733, y João Currim, en 1765. En ambos casos, se trataba de clérigos seculares formados en Teología en las Universidades de Évora, el primero, y de Coimbra, el segundo. Hugo Maguire era oriundo del condado de Galway o del de Fermanag y João Currim procedía del de Wexford. Ahora bien, mientras Maguire era canónigo en la catedral de Funchal, en Madeira, Currim solo era vicario en la iglesia de Alvorge, en el obispado de Coimbra ${ }^{35}$.

Lógicamente, también eran extranjeros algunos calificadores y revisores de libros $^{36}$. Que sepamos, hubo catorce calificadores no naturales pero seguramente debieron servir más de los que conocemos, porque algunos de los religiosos que desempeñaron este oficio no llegaron nunca a tener provisión del inquisidor general ni a pasar una prueba de limpieza de sangre. Así, por ejemplo, en 1713, cuando fray Francisco Marim, irlandés, solicitó ingresar en el Santo Oficio, afirmó que ya había calificado varias veces conclusiones de Teología y Filosofía, y que el inquisidor de Coimbra Afonso Cabral Botelho le había encargado en algunas ocasiones negocios que competían a los calificadores ${ }^{37}$. Y Gabriel Talbott, muchos años antes de obtener la provisión de calificador del Santo

32 El abuelo de Pedro Vivas de Carvajo era, como decimos, natural de Castelo da Vide. Después de la incorporación de Portugal a la Monarquía Hispánica, en 1581, casó en Valencia de Alcántara, donde llegó a ser regidor perpetuo. Por su parte, Pedro Vivas de Carvajo se trasladó a Castelo da Vide cuando las tropas portuguesas tomaron Valencia de Alcántara en 1664. Allí permaneció con su tío, João Vivas Barba, prior de la iglesia de Santiago, hasta que se trasladó a la Universidad de Coimbra. Mientras, su padre, que era labrador, permaneció en Valencia donde ostentó, además, la honra de regidor perpetuo. En Portugal, varios miembros de la familia de Pedro Vivas de Carvajo habían seguido la carrera eclesiástica. Así, jesuitas eran su tío Lourenço Vivas y sus primos Pedro de Sequeira, rector del colegio de la Compañía en Faro, y Gonçalo de Sequeira, rector del colegio de Portalegre.

33 ANTT, TSO, CG, Habilitações, mç. 105, doc. 1751 (Juan de Membrive); mç. 8, doc. 235 (Pedro Vivas de Carvajo); mç. 83, doc. 1437 (Francisco Tudela de Castilho).

34 Domínguez OrTiZ, Antonio, Los extranjeros en la vida española durante el siglo XVII y otros artículos, Sevilla, Diputación Provincial, 1996, pág. 117.

35 ANTT, TSO, CG, Habilitações, mç. 1, doc. 1 (Hugo Maguire); mç. 129, doc. 2002 (João Currim).

36 Según Ana Catarina da Fonseca, solo hubo dos revisores extranjeros, Pedro Paulo Ferrer y Carlos da Madre de Deus, lo que se debe a que esta autora circunscribe su estudio a los personajes que ejercieron de censores de obras impresas. FONSECA, Ana Catarina Lopes da, O Censor Literário na Época Moderna: o perfil do revedor de livros ao serviço do Santo Ofício (1580-1640), tesis de máster, Lisboa, UNL, 2006, pág. 54.

37 ANTT, TSO, Habilitações, mç. 121, doc. 1819 (Francisco Marim), fol. 1r: Petición del pretendiente. 
Oficio, censuraba por orden del tribunal los libros ingleses y franceses que entraban en Oporto ${ }^{38}$.

\section{CUADRO 1: COMISARIOS EXTRANJEROS EN EL SANTO OFICIO PORTUGUÉS}

\begin{tabular}{|c|c|c|c|c|}
\hline $\begin{array}{l}\text { Año de } \\
\text { ingreso } \\
\text { en el SO }\end{array}$ & Nombre & Nacimiento & $\begin{array}{l}\text { Formación } \\
\text { académica }\end{array}$ & Ocupación eclesiástica \\
\hline 1611 & $\begin{array}{l}\text { Juan de } \\
\text { Membrive }\end{array}$ & $\begin{array}{l}\text { España } \\
\text { Obispado de } \\
\text { Sigüenza }\end{array}$ & Desconocida & Desconocida. \\
\hline 1684 & $\begin{array}{l}\text { Pedro } \\
\text { Vivas de } \\
\text { Carvajo }\end{array}$ & $\begin{array}{l}\text { España } \\
\text { Obispado de } \\
\text { Badajoz }\end{array}$ & $\begin{array}{l}\text { Cánones } \\
\text { U. Coimbra }\end{array}$ & $\begin{array}{l}\text { Vicario general de la ouvi- } \\
\text { doria de Abrantes }\end{array}$ \\
\hline 1733 & $\begin{array}{l}\text { Hugo } \\
\text { Maguire }\end{array}$ & $\begin{array}{l}\text { Irlanda } \\
\text { Condados de } \\
\text { Galway o de } \\
\text { Fermanag }\end{array}$ & $\begin{array}{l}\text { Teología } \\
\text { U. Évora }\end{array}$ & Canónigo en Funchal. \\
\hline 1755 & $\begin{array}{l}\text { Francisco } \\
\text { Tudela de } \\
\text { Castilho y } \\
\text { Costa }\end{array}$ & $\begin{array}{l}\text { España } \\
\text { Obispado de } \\
\text { Badajoz }\end{array}$ & Desconocida & $\begin{array}{l}\text { Prior de la iglesia de Nossa } \\
\text { Senhora da Consolação, en } \\
\text { Santo Estevão (Sortelha), } \\
\text { obispado de Guarda. }\end{array}$ \\
\hline 1765 & $\begin{array}{l}\text { João Cu- } \\
\text { rrim }\end{array}$ & $\begin{array}{l}\text { Irlanda } \\
\text { Condado de } \\
\text { Wexford }\end{array}$ & $\begin{array}{l}\text { Teología. } \\
\text { U. Coimbra }\end{array}$ & $\begin{array}{l}\text { Vicario en Algove, obispa- } \\
\text { do de Coimbra. }\end{array}$ \\
\hline
\end{tabular}

Fuentes: ANTT, TSO, CG, Habilitações, mç. 1, doc. 1 (Hugo Maguire); mç. 8, doc. 235 (Pedro Vivas de Carvajo); mç. 83, doc. 1437 (Francisco Tudela de Castilho); mç. 105, doc. 1751 (Juan de Membrive), y mç. 129, doc. 2002 (João Currim).

El único español que desempeñó el oficio de calificador del tribunal portugués fue el padre Pedro Paulo Ferrer, S.J., natural de Málaga, que ingresó en el Santo Oficio en 159539. También eran jesuitas los italianos Carlos António Casnedi y Alexandre Perié. El padre Casnedi era natural de Milán y calificador del tribunal de Toledo, en España ${ }^{40}$. Y el padre Perié, natural de Turín y mo-

38 ANTT, TSO, Habilitações, mç. 3, doc. 25 (Gabriel Talbott), fol. 2r: Petición del pretendiente.

39 Pedro Paulo Ferrer había estudiado latín en Málaga. Más tarde, pasó a la Universidad de Baeza y opositó a la canonjía magistral de la catedral de Málaga. Después ingresó en la Compañía de Jesús y se trasladó a Portugal, al colegio de Évora. ANTT, TSO, CG, Habilitações, mç. 39, doc. 673 (Pedro Paulo Ferrer).

40 ANTT, TSO, CG, Habilitações, maço 1, doc. 16 (Carlos António Casnede). En la habilitación declararon cuatro jesuitas, todos ellos portugueses, y el tribunal no preguntó sobre los padres y abuelos del padre Casnede. 
rador en el colegio de la Compañía en Bahía, fue nombrado comisario del Santo Oficio en 1713. Franceses eran fray Constantino de Nantes, fray Aleixo Josselin y fray Francisco de Pontable, capuchinos procedentes de Bretaña, que ingresaron en el Santo Oficio en 1676, 1695 y 1703, respectivamente.

Sin lugar a dudas, el grupo más numeroso de extranjeros que sirvieron como calificadores y censores del tribunal portugués fue el de los irlandeses. De Irlanda procedían los franciscanos de la provincia de los Algarves fray Carlos da Madre de Deus, que ingresó en 1620, y fray Francisco Marim, en 1714; los dominicos fray Patrício de São Tomé y fray Pedro da Encarnação, nombrados en 1676 y 1686, respectivamente; el agustino fray Domingos Daly, que ingresó en 1695, y el oratoniano Gabriel Talbott, que lo hizo en 1731.

Un caso especial es del de Federico Retz, religioso teatino natural de Dinamarca. Era hijo de Jorge Retz, caballero de la orden del Elefante, consejero de Estado en Dinamarca y embajador del rey danés ante Felipe IV. Su abuelo paterno, Federico Retz, había sido caballero de la orden del Elefante, senador del reino y gobernador de Vordingborg. Y el materno, Nicolás Trolle, había sido señor de Trolholm (Finlandia), caballero de la orden del Elefante y senador del reino. En Madrid, mientras ejercía como embajador del rey danés, Jorge Retz se convirtió al catolicismo junto con su mujer y sus hijos. Por ello, Cristian $\mathrm{V}$ le privó del cargo y le confiscó sus bienes. A cambio, Carlos II hizo merced a su viuda, Margarita Trolle, de una pensión de 2.000 cruzados, en 1677, y de un título ducal en Nápoles, en 1678. Nada más convertirse al catolicismo, Federico Retz, un niño de once años, pasó a estudiar con los teatinos. Después hizo el noviciado en Génova y de ahí pasó para Roma, donde fue secretario del general de su orden. Cuando solicitó ingresar en el Santo Oficio, Retz contaba ya con carta de naturaleza y estaba llevando a cabo un proceso de integración en Portugal, donde también vivía su hermana ${ }^{41}$. Resulta muy interesante que el Santo Oficio no considerase un impedimento el hecho de que Retz y sus antepasados hubieran sido luteranos. Según el tribunal de Lisboa, el danés era «digno de favor por deixar a seita dos erros, em que seus país o havião criado por seguir e abraçar nossa Santa Fee Catholica» ${ }^{42}$.

Como es lógico, algunos visitadores de naves también eran extranjeros. Es el caso del padre Nicolau Astão, natural de Inglaterra, cuya prueba de limpieza de sangre o no llegó a realizarse o se ha perdido ${ }^{43}$. Y, asimismo, eran forasteros

41 ANTT, Chancelaria de D. Pedro II, Doações, liv. 42, fol. 50 (Carta de naturalización) y liv. 46, fols. 300v-301r (Carta para poder desempeñar oficios en su religión).

42 ANTT, TSO, CG, Habilitações, maço 1, doc. 1 (Federico Retz). Sobre el título ducal en Nápoles concedido a Margarita Trolle, vid. Álvarez-Ossorio Alvariño, Antonio, «De la conservación a la desmembración. Las provincias italianas y la monarquía de España», Stvdia Historica. Historia Moderna, 26 (2004), págs. 207-208.

43 Sobre los visitadores de naves, vid. Domingos, Manuela, «Visitas do Santo Ofício às Naus Estrangeiras. Regimentos e Quotidianos», Revista da Biblioteca Nacional, 2. ${ }^{a}$ série, vol. 8, n. ${ }^{\circ} 1$ (1993), págs. 117-129. 
los intérpretes del Santo Oficio, aunque, al igual que ocurre en el caso de los calificadores, desconocemos su número exacto, pues había quien servía sin tener provisión del inquisidor general y, por lo tanto, sin haber pasado una prueba de limpieza de sangre. De hecho, solo contamos con las pruebas de limpieza de sangre de cuatro intérpretes o línguas, si bien fueron muchos más los que desempeñaron esta tarea ${ }^{44}$.

No obstante, durante el siglo XVIII —es decir, cuando más extranjeros ingresan en el Santo Oficio- no hubo, que sepamos, ningún diputado ni inquisidor nacido fuera de Portugal. Entre los oficiales de rango superior, solo tenemos noticia de Julião Cataldi, nacido en Italia y naturalizado en Portugal, que fue nombrado notario del tribunal de Lisboa en $1788^{45}$. Junto a él, los únicos oficiales extranjeros del siglo XVIII — todos del tribunal de Lisboa- fueron los españoles Martín Nicolás Gil y Juan Antonio Fernández y el francés João Baptista dos Santos. Gil fue nombrado médico extra-numerario en 1762; Fernández fue designado oficial de la vara del meirinbo en 1798, y Santos obtuvo el oficio de cirujano en $1816^{46}$. No obstante, João Baptista dos Santos no era, propiamente, un extranjero porque aunque había nacido en Chatillon, en Francia, era hijo de un portugués y de una francesa y había casado en Lisboa, también con una natural. Ahora bien, fue necesario que el inquisidor general estableciese como "patria común» la ciudad de Lisboa para realizar allí las pruebas de limpieza que deberían hacerse en Francia ${ }^{47}$.

\section{UN CASO ESPECIAL: LAS PRUEBAS DE LIMPIEZA DE SANGRE DE LOS ESPAÑOLES}

Que sepamos, hubo al menos un inquisidor —Bartolomé de Monteagudo_-, dos diputados —Alfonso Coloma y Diego de Salazar_- tres comisarios — Juan de Membrive, Pedro Vivas de Carvajo y Francisco Tudela de Castilho_-, un calificador - Pedro Paulo Ferrer - y en torno a 60 familiares nacidos en España ${ }^{48}$. De

44 Tenemos la prueba de limpieza de sangre de Cláudio Monteiro y de su hijo João Monteiro, ambos cónsules franceses en Aveiro, que desempeñaron el oficio de intérpretes y que obtuvieron cartas de familiares del Santo Oficio en 1655 y 1671, respectivamente. ANTT, TSO, CG, Habilitações, mç. 1, doc. 1 (Cláudio Monteiro); mç. 11, doc. 343 (João Monteiro).

45 ANTT, TSO, IL, liv. 122, fols. 258v: Provisión de don Inácio de São Caetano, inquisidor general, del 28 de abril de 1788 . Julião Cataldi había sido naturalizado por decreto de la reina doña Maria I del 27 de marzo de 1788.

46 ANTT, TSO, IL, mç. 68, n. 37: Requerimento do doutor Martinbo Nicolau Gil, familiar do Santo Ofício, a solicitar o lugar de médico extranumerário dos cárceres da Inquisição de Lisboa (1762). La provisión de Martín Nicolás Gil es del 9 de noviembre de 1762. ANTT, TSO, CG, Habilitações, mç. 174, doc. 1538 (João António Fernandes). ANTT, TSO, IL, liv. 124, fol. 6v: Provisión de João Baptista dos Santos como cirujano del tribunal de Lisboa (11 de octubre de 1816).

47 ANTT, TSO, CG, Habilitações, mç. 174, doc. 1544 (João Baptista dos Santos).

48 No hemos considerado castellano al inquisidor Sebastião de Matos de Noronha porque, aunque nació en Madrid, era hijo de los portugueses Rui de Matos de Noronha, del Consejo de 
hecho, la mayor parte de los familiares del Santo Oficio nacidos fuera de Portugal eran españoles y entre estos predominaban, como es lógico, los gallegos (casi el 80\%).

CUADRO 2: FAMILIARES ESPAÑOLES DEL SANTO OFICIO PORTUGUÉS

\begin{tabular}{|c|c|c|c|c|c|c|c|}
\hline Año & Nombre & Origen & Profesión & Año & Nombre & Origen & Profesión \\
\hline 1612 & $\begin{array}{l}\text { Hernan- } \\
\text { do de } \\
\text { Espina }\end{array}$ & Castilla & - & 1757 & $\begin{array}{l}\text { Pedro } \\
\text { Telmo } \\
\text { Lima }\end{array}$ & Galicia & Mercader \\
\hline 1620 & $\begin{array}{l}\text { Domingo } \\
\text { Lago }\end{array}$ & Galicia & Piloto & 1759 & $\begin{array}{l}\text { Esteban } \\
\text { Rodríguez } \\
\text { Álvarez }\end{array}$ & Galicia & $\begin{array}{l}\text { Sargento } \\
\text { mayor }\end{array}$ \\
\hline 1620 & $\begin{array}{l}\text { Pedro de } \\
\text { Ovando }\end{array}$ & $\begin{array}{l}\text { Andalu- } \\
\text { cía }\end{array}$ & $\begin{array}{l}\text { Capitán de } \\
\text { navíos }\end{array}$ & 1761 & $\begin{array}{l}\text { Juan } \\
\text { Henrí- } \\
\text { quez }\end{array}$ & Galicia & $\begin{array}{l}\text { Hombre } \\
\text { de nego- } \\
\text { cios }\end{array}$ \\
\hline 1628 & $\begin{array}{l}\text { Pedro } \\
\text { González } \\
\text { Bacelar }\end{array}$ & Galicia & - & 1761 & $\begin{array}{l}\text { Simón de } \\
\text { Silva } \\
\text { Falcón }\end{array}$ & Galicia & Orfebre \\
\hline 1683 & $\begin{array}{l}\text { Diego } \\
\text { Vázquez }\end{array}$ & Galicia & Criado & 1762 & $\begin{array}{l}\text { Lorenzo } \\
\text { Fernández } \\
\text { Crespo }\end{array}$ & Galicia & $\begin{array}{l}\text { Hombre } \\
\text { de nego- } \\
\text { cios }\end{array}$ \\
\hline 1691 & $\begin{array}{l}\text { Antonio } \\
\text { Cortés } \\
\text { Bermen }\end{array}$ & $\begin{array}{l}\text { Andalu- } \\
\text { cía }\end{array}$ & Orfebre & 1762 & $\begin{array}{l}\text { Martín } \\
\text { Nicolás } \\
\text { Gil }\end{array}$ & Galicia & Médico \\
\hline 1714 & $\begin{array}{l}\text { Juan } \\
\text { Garfias } \\
\text { Torres }\end{array}$ & $\begin{array}{l}\text { Andalu- } \\
\text { cía }\end{array}$ & Juez & 1763 & $\begin{array}{l}\text { Anselmo } \\
\text { Antonio } \\
\text { Blanco }\end{array}$ & Galicia & $\begin{array}{l}\text { Mercader } \\
\text { de vinos }\end{array}$ \\
\hline 1717 & $\begin{array}{l}\text { Antonio } \\
\text { Meylán }\end{array}$ & Galicia & Mercader & 1763 & $\begin{array}{l}\text { Antonio } \\
\text { Rodrí- } \\
\text { guez }\end{array}$ & Galicia & $\begin{array}{l}\text { Hombre } \\
\text { de nego- } \\
\text { cios. Mer- } \\
\text { cader de } \\
\text { madera. }\end{array}$ \\
\hline 1718 & $\begin{array}{l}\text { Diego } \\
\text { Márquez } \\
\text { de Prado }\end{array}$ & $\begin{array}{l}\text { Extre- } \\
\text { madura }\end{array}$ & $\begin{array}{l}\text { Capitán de } \\
\text { caballos }\end{array}$ & 1765 & $\begin{array}{l}\text { Francisco } \\
\text { Antonio } \\
\text { Suarez de } \\
\text { Castro }\end{array}$ & Galicia & $\begin{array}{l}\text { Hombre } \\
\text { de nego- } \\
\text { cios }\end{array}$ \\
\hline 1732 & $\begin{array}{l}\text { José Alves } \\
\text { de Brito } \\
\text { Pedro }\end{array}$ & Galicia & Orfebre & 1766 & $\begin{array}{l}\text { Felipe de } \\
\text { los Santos } \\
\text { Juan }\end{array}$ & Galicia & $\begin{array}{l}\text { Hombre de } \\
\text { negocios } \\
\text { Hombre }\end{array}$ \\
\hline 1734 & $\begin{array}{l}\text { Vicente } \\
\text { Vidal }\end{array}$ & Valencia & Ingeniero & 1767 & $\begin{array}{l}\text { Antonio } \\
\text { Estévez }\end{array}$ & Galicia & $\begin{array}{l}\text { de nego- } \\
\text { cios }\end{array}$ \\
\hline
\end{tabular}

Portugal, y doña Filipa Cardosa. Tampoco hemos contado entre los familiares extranjeros a Miguel Soares de Vasconcelos Brito de Almeida, Pedro Soares de Melo, Diogo de Mendonça Corte Real y Joaquim Eugénio de Lucena Almeida e Noronha, nacidos en Castilla, porque eran hijos de portugueses. Asimismo era portugués José Ribeiro de Andrade porque, aunque nacido en Vigo, sus padres procedían ambos del arzobispado de Braga. 


\begin{tabular}{|c|c|c|c|c|c|c|c|}
\hline Año & Nombre & Origen & Profesión & Año & Nombre & Origen & Profesión \\
\hline 1740 & $\begin{array}{l}\text { Alberto } \\
\text { de Abreu }\end{array}$ & Galicia & $\begin{array}{l}\text { Hombre de } \\
\text { negocios y } \\
\text { comisario } \\
\text { de la carre- } \\
\text { ra de Bahía }\end{array}$ & 1767 & $\begin{array}{l}\text { Joaquín } \\
\text { Giesteira } \\
\text { Pazos }\end{array}$ & Galicia & $\begin{array}{l}\text { Hombre } \\
\text { de nego- } \\
\text { cios }\end{array}$ \\
\hline 1741 & $\begin{array}{l}\text { José Do- } \\
\text { mínguez }\end{array}$ & Galicia & $\begin{array}{l}\text { Comisario } \\
\text { de la carre- } \\
\text { ra de Ma- } \\
\text { ranhão }\end{array}$ & 1767 & $\begin{array}{l}\text { José } \\
\text { Francisco } \\
\text { Blanco }\end{array}$ & Galicia & $\begin{array}{l}\text { Hombre } \\
\text { de nego- } \\
\text { cios }\end{array}$ \\
\hline 1741 & $\begin{array}{l}\text { Simón } \\
\text { Rodrí- } \\
\text { guez }\end{array}$ & Galicia & Fundidor & 1768 & $\begin{array}{l}\text { Vicente } \\
\text { Preto } \\
\text { Guedes }\end{array}$ & Galicia & Mercader \\
\hline 1743 & $\begin{array}{l}\text { Tomás } \\
\text { José Ra- } \\
\text { maza }\end{array}$ & Galicia & $\begin{array}{l}\text { Hombre } \\
\text { de nego- } \\
\text { cios }\end{array}$ & 1769 & $\begin{array}{l}\text { Juan } \\
\text { Francisco }\end{array}$ & Galicia & $\begin{array}{l}\text { Hombre } \\
\text { de nego- } \\
\text { cios }\end{array}$ \\
\hline 1744 & $\begin{array}{l}\text { Francisco } \\
\text { de los } \\
\text { Santos de } \\
\text { Abreu }\end{array}$ & Galicia & $\begin{array}{l}\text { Hombre } \\
\text { de nego- } \\
\text { cios }\end{array}$ & 1769 & $\begin{array}{l}\text { Simón de } \\
\text { Araujo }\end{array}$ & Galicia & $\begin{array}{l}\text { Hombre } \\
\text { de nego- } \\
\text { cios y } \\
\text { comisario } \\
\text { de trigos }\end{array}$ \\
\hline 1746 & $\begin{array}{l}\text { Antonio } \\
\text { González } \\
\text { Prego }\end{array}$ & Galicia & $\begin{array}{l}\text { Comisario } \\
\text { de la carre- } \\
\text { ra de Ma- } \\
\text { ranhão }\end{array}$ & 1770 & $\begin{array}{l}\text { Benito } \\
\text { Fernán- } \\
\text { dez Lima }\end{array}$ & Galicia & $\begin{array}{l}\text { Vive de su } \\
\text { hacienda }\end{array}$ \\
\hline 1746 & $\begin{array}{l}\text { Mateo } \\
\text { Juver }\end{array}$ & $\begin{array}{l}\text { Catalu- } \\
\text { ña }\end{array}$ & Médico & 1771 & $\begin{array}{l}\text { Manuel } \\
\text { Díaz }\end{array}$ & Galicia & $\begin{array}{l}\text { Hombre } \\
\text { de nego- } \\
\text { cios }\end{array}$ \\
\hline 1747 & $\begin{array}{l}\text { Bartolomé } \\
\text { Manuel } \\
\text { Silvestre } \\
\text { de Araña }\end{array}$ & $\begin{array}{l}\text { Andalu- } \\
\text { cía }\end{array}$ & Picador & 1772 & $\begin{array}{l}\text { Pedro } \\
\text { González } \\
\text { San Ro- } \\
\text { mán }\end{array}$ & León & Piloto \\
\hline 1748 & $\begin{array}{l}\text { Domingo } \\
\text { Vaz }\end{array}$ & Galicia & $\begin{array}{l}\text { Mercader } \\
\text { y hombre } \\
\text { de nego- } \\
\text { cios }\end{array}$ & 1772 & $\begin{array}{l}\text { Francisco } \\
\text { de Silva } \\
\text { Pumar }\end{array}$ & Galicia & $\begin{array}{l}\text { Hombre } \\
\text { de nego- } \\
\text { cios }\end{array}$ \\
\hline 1748 & $\begin{array}{l}\text { Juan de } \\
\text { la Silva } \\
\text { Ledo }\end{array}$ & Galicia & $\begin{array}{l}\text { Hombre } \\
\text { de nego- } \\
\text { cios }\end{array}$ & 1773 & $\begin{array}{l}\text { Francisco } \\
\text { Vázquez }\end{array}$ & Galicia & Cirujano \\
\hline 1749 & $\begin{array}{l}\text { Jacinto } \\
\text { Araujo } \\
\text { Ramallo }\end{array}$ & Galicia & Mercader & 1775 & $\begin{array}{l}\text { Antonio } \\
\text { de Sousa } \\
\text { Lima }\end{array}$ & Galicia & $\begin{array}{l}\text { Mercader y } \\
\text { hombre de } \\
\text { negocios }\end{array}$ \\
\hline 1749 & $\begin{array}{l}\text { Raimun- } \\
\text { do de } \\
\text { Freixas }\end{array}$ & $\begin{array}{l}\text { Catalu- } \\
\text { ña }\end{array}$ & $\begin{array}{l}\text { Hombre } \\
\text { de nego- } \\
\text { cios }\end{array}$ & 1783 & $\begin{array}{l}\text { Gregorio } \\
\text { Núñez }\end{array}$ & Galicia & $\begin{array}{l}\text { Hombre } \\
\text { de nego- } \\
\text { cios }\end{array}$ \\
\hline 1753 & $\begin{array}{l}\text { Juan } \\
\text { Antonio } \\
\text { de Acuña }\end{array}$ & $\begin{array}{l}\text { Andalu- } \\
\text { cía }\end{array}$ & $\begin{array}{l}\text { Hombre } \\
\text { de nego- } \\
\text { cios }\end{array}$ & 1783 & $\begin{array}{l}\text { Jerónimo } \\
\text { Francisco } \\
\text { de Molina }\end{array}$ & $\begin{array}{l}\text { Andalu- } \\
\text { cía }\end{array}$ & $\begin{array}{l}\text { Fabricante } \\
\text { de galones }\end{array}$ \\
\hline 1754 & $\begin{array}{l}\text { Juan } \\
\text { González } \\
\text { Rebelo }\end{array}$ & Galicia & $\begin{array}{l}\text { Hombre } \\
\text { de nego- } \\
\text { cios }\end{array}$ & 1784 & $\begin{array}{l}\text { Juan } \\
\text { Antonio } \\
\text { Rodríguez }\end{array}$ & Galicia & $\begin{array}{l}\text { Hombre } \\
\text { de nego- } \\
\text { cios }\end{array}$ \\
\hline
\end{tabular}




\begin{tabular}{|c|c|c|c|c|c|c|c|}
\hline Año & Nombre & Origen & Profesión & Año & Nombre & Origen & Profesión \\
\hline 1754 & $\begin{array}{l}\text { Juan } \\
\text { Pinto } \\
\text { González }\end{array}$ & León & Boticario & 1788 & $\begin{array}{l}\text { Agustín } \\
\text { Alonso }\end{array}$ & Galicia & $\begin{array}{l}\text { Cabo de la } \\
\text { guardia } \\
\text { real }\end{array}$ \\
\hline 1756 & $\begin{array}{l}\text { Blas } \\
\text { Lorenzo }\end{array}$ & Galicia & $\begin{array}{l}\text { Hombre } \\
\text { de nego- } \\
\text { cios }\end{array}$ & 1789 & $\begin{array}{l}\text { Benito } \\
\text { González } \\
\text { Aires }\end{array}$ & Galicia & $\begin{array}{l}\text { Mercader } \\
\text { de tienda }\end{array}$ \\
\hline 1757 & $\begin{array}{l}\text { Antonio } \\
\text { Fernán- } \\
\text { dez Porto }\end{array}$ & Galicia & $\begin{array}{l}\text { Hombre } \\
\text { de nego- } \\
\text { cios }\end{array}$ & 1795 & $\begin{array}{l}\text { Bernardo } \\
\text { de la } \\
\text { Villa }\end{array}$ & Galicia & $\begin{array}{l}\text { Hombre } \\
\text { de nego- } \\
\text { cios }\end{array}$ \\
\hline 1757 & $\begin{array}{l}\text { Francisco } \\
\text { Crespo }\end{array}$ & Galicia & $\begin{array}{l}\text { Hombre } \\
\text { de nego- } \\
\text { cios }\end{array}$ & & & & \\
\hline
\end{tabular}

Fuentes: ANTT, TSO, IL, liv. 104-123; IE, liv. 148, 149, 151; IC, liv. 252, 253, 259, 261.

ANTT, TSO, CG, Habilitações, mç. 2, doc. 107 (Hernando); mç. 2, doc. 51 (Domingo); mç. 1, doc. 28 (Pedro); mç. 5, doc. 143 (Diogo); mç. 33, doc. 841 (António); mç. 51, doc. 988 (João); mç. 61, doc. 1246 (António); mç. 13, doc. 274 (Diogo); mç. 36, doc. 579 (José); mç. 22, doc. 438 (Pedro); mç. 1, doc. 10 (Alberto); mç. 46, doc. 737 (José); mç. 8, doc. 138 (Simão); mç. 63, doc. 1217 (Francisco); mç. 4, doc. 57 (Mateus); mç. 5, doc. 90 (Bartolomeu); mç. 36, doc. 637 (Domingos); mç. 88, doc, 1528 (João); mç. 4, doc. 52 (Jacinto); mç. 1, doc. 4 (Raimundo); mç. 101, doc. 1681 (João); mç. 103, doc, 1712 (João); mç. 5, doc, 62 (Brás); mç. 131, doc. 2202 (António); mç. 86, doc. 1475 (Francisco); mç. 30, doc, 547 (Pedro); mç. 5, doc, 68 (Estévão); mç. 10, doc, 162 (Simão); mç. 4, doc, 85 (Martinho); mç. 1, doc, 14 (Anselmo); mç. 150, doc, 2401 (António); mç. 98, doc, 1611 (Francisco); mç. 134, doc, 2060 (João); mç. 11, doc, 140 (Joaquim); mç. 108, doc, 2509 (José); mç. 7, doc. 102 (Vicente); mç. 139, doc, 2121 (João); mç. 11, doc, 168 (Simão); mç. 15, doc, 211 (Bento); mç. 223, doc. 1331 (Manuel); mç. 36, doc, 619 (Pedro); mç. 116, doc, 1754 (Francisco); mç. 120, doc, 1798 (Francisco); mç. 188, doc, 2778 (António); mç. 5, doc, 73 (Gregório); mç. 13, doc, 191 (Jerónimo); mç. 162, doc, 1346 (João); mç. 7 , doc, 103; mç. 17, doc, 235 (Bento); mç. 15, doc. 505 (Bernardo).

En estos casos, los interrogatorios sobre la limpieza de sangre de los pretendientes a familiares fueron realizados por parte de los diferentes tribunales de distrito del Santo Oficio español en las zonas de donde eran originarios ellos y sus padres. Así, cuando un español solicitaba ingresar en el Santo Oficio luso, el tribunal de distrito portugués - Lisboa, Coimbra o Évora- enviaba una carta requisitoria al tribunal de distrito español correspondiente. No obstante, hubo casos en los que los inquisidores portugueses se equivocaron de tribunal. Así, en 1594, los inquisidores de Lisboa pidieron a los de Sevilla que ordenasen realizar la prueba de limpieza de sangre de Pedro Paulo Ferrer en Málaga que, sin embargo, pertenecía al distrito de Granada. Y en 1745, el tribunal de Lisboa pidió al de Barcelona que hiciese los interrogatorios sobre Mateo Juver en Tortosa que, en realidad, pertenecía al distrito de la inquisición de Valencia ${ }^{49}$.

Como es evidente, durante la Guerra de Restauración se limitaron —aunque no llegaron a interrumpirse - las relaciones entre los tribunales de la Inquisición

49 ANTT, TSO, CG, Habilitações, mç. 39, doc. 673 (Pedro Paulo Ferrer); mç. 4, doc. 57 (Mateus Juver). 
de España y Portugal. Por ello, las pruebas de Francisco Díaz de Barros, que tenía un abuelo gallego, tuvieron que hacerse en Lisboa ${ }^{50}$. El diputado del Conselho Geral que examinó su proceso aclaró:

«me parece que esta habilitado para poder servir o Santo Officio sem embargo de se não fazer diligencias na terra dos avos maternos por quanto não he posivel por serem de Galisa e gente muito ordinaria que provavelmente não tiveram mistura com gente da nação» ${ }^{51}$.

Hubo un caso en el que el Santo Oficio portugués intentó que sus propios comisarios realizasen en España la información sobre la limpieza de sangre del pretendiente a una familiatura. En la carta requisitoria que los inquisidores de Lisboa enviaron a los de Évora para que ordenasen a un comisario realizar la información sobre Pedro Vivas de Carvajo, no se establecía diferencia alguna entre las villas de Valencia de Alcántara, en España, y de Castelo da Vide, en Portugal $^{52}$. Sin embargo, los inquisidores de Évora solo ordenaron al comisario de Castelo da Vide que indagase en esta villa. Por ello, dos meses después de la requisitoria anterior, el tribunal de Lisboa tuvo que enviar otra, esta vez dirigida a los inquisidores de Llerena, en cuyo distrito se encontraba la villa de Valencia de Alcántara.

\section{LOS EXTRANJEROS NO PENINSULARES Y LA CUESTIÓN DE LA «PATRIA COMÚN»}

A diferencia de lo que ocurría con los españoles que deseaban ingresar en el Santo Oficio portugués, cuyas informaciones de limpieza de sangre eran realizadas por el tribunal de distrito correspondiente, las indagaciones sobre el resto de extranjeros tenían que hacerse necesariamente en Portugal. En esos casos, la Inquisición recurría, sobre todo, a testigos procedentes de los mismos países que el pretendiente, para averiguar su limpieza y legitimidad, y a religiosos de sus conventos, a fin de conocer su vida y costumbres.

Un aspecto muy interesante de las habilitaciones de los extranjeros es la cuestión de la «patria común». Normalmente, las diligencias de los no natura-

50 Francisco Díaz de Barros era natural de Galicia. Su madre, los abuelos paternos y la abuela materna eran de Lisboa y su padre y el abuelo materno de Galicia.

51 Voto de Francisco Cardoso de Torneo del 21 de septiembre de 1642. Sin embargo, al año siguiente el Conselho Geral decidió quitar a Francisco Díaz de Barros la carta de familiar del Santo Oficio porque había casado con una mujer que tenía sangre conversa. ANTT, TSO, CG, Habilitações, mç. 6, doc. 256 (Francisco Dias de Bairros).

52 «e logo nas ditas villas de Valença de Alcantara e Castello de Vide e parte que parecer mais accomodada para esta diligencia se fazer como convem, [o comissário] mandara vir perante si athe treze ou quatorze testemunhas ao todo, sette ou oito em Valença e em Castello de Vide cinco ou seis, pessoas antigas, christãas velhas legaes e fidedignas que tenhão rezão de bem conhecer as atrazas nomeadas». ANTT, TSO, CG, Habilitações, mç. 8, doc. 235, fls. 8r-10r (Pedro Vivas de Carvalho). 
les se realizaban en Lisboa, considerada patria común de todos a semejanza de Roma, la patria de cualquier ciudadano del Imperio ${ }^{53}$. Sin duda, el mayor número de extranjeros residentes en Portugal se concentraba en la ciudad del Tajo. Además, allí existían varios conventos y hospitales de extranjeros, donde la Inquisición podía encontrar testigos procedentes de las mismas regiones que los pretendientes a ingresar en el Santo Oficio. Entre estas instituciones religiosas destacaban el convento de la Porciúncula, de capuchinos franceses, el de Nuestra Señora del Rosario, de dominicos irlandeses, y el del Bom Sucesso, de dominicas de Irlanda.

El convento de Nossa Senhora do Rosário, también llamado colegio del Corpo Santo o de Corte Real, porque se encontraba próximo al palacio de los Moura, pertenecía a los dominicos irlandeses. Fue fundado en 1659 por la reina doña Luisa de Guzmán, a petición del dominico irlandés fray Domingos do Rosário ${ }^{54}$. En este colegio eran profesores fray Patrício de São Tomé y fray Pedro da Encarnação, ambos naturales del puerto de Dingle, que ingresaron en el Santo Oficio como calificadores en 1676 y 1686, respectivamente. Además, buena parte de los testigos de las habilitaciones de los irlandeses que sirvieron al Santo Oficio como comisarios y calificadores eran también religiosos de este convento ${ }^{55}$. Asimismo, hubo un testigo que era confesor de las religiosas del Bom Sucesso de Lisboa, un convento de dominicas irlandesas fundado también por fray Domingos do Rosário ${ }^{56}$.

Por su parte, el convento de Nossa Senhora dos Anjos da Porciúncula había sido fundado en 1648 por fray Cirilo de Mayenne, capuchino francés de la pro-

53 Del mismo modo, los flamencos que deseaban ingresar en las Órdenes Militares españolas pedían que sus informaciones se hicieran en Madrid, por ser también "patria común». Vid. GLESENER, Thomas, «Poder y sociabilidad: las élites flamencas en España a través de los expedientes de las Órdenes Militares (siglo XVIII)» en: CreSPo SOlAnA, Ana y Herrero SánCHEZ, Manuel, España y las 17 provincias de los Países Bajos. Una revisión historiográfica (XVI-XVIII), Córdoba, Servicio de Publicaciones de la Universidad de Córdoba, 2002, vol, 1, págs. 169-188.

54 Santa Catarina, Fr. Lucas de, História de S. Domingos particular do reino e conquistas de Portugal, Cuarta Parte, Porto, Lello \& Irmão, 1977 [1767], págs. 1176 y ss. Sobre este convento, vid. Santos, João Bernardo dos, Convento dos Dominicanos Irlandeses do Corpo Santo, Lisboa, 1960.

55 En las habilitaciones de los irlandeses que deseaban servir al Santo Oficio como comisarios y calificadores, declararon los siguientes dominicos irlandeses del colegio de Nuestra Señora del Rosario: Fr. Lourenço Barry y Fr. Pedro da Encarnação, en 1676; Fr. Lourenço Barry, Fr. António do Rosário, Fr. Luís do Rosário, Fr. Domingos O’Sullivan y Fr. João de São Tomé, en 1686; Fr. António do Rosário, Fr. Guillermo O’Droyer, Fr. João O’Farrell, Fr. Duarte Fern, Fr. Pedro MacLean y Fr. Guillerme Elligott, en 1695; Fr. Humberto de Burgo, Fr. Bernardo Brullaughan, Fr. Tomé MacHugo, Fr. João Mauricio de São Tomé, Fr. Martinho de Burgo, Fr. Domingos de São Tomé y Fr. Patrício de São Tomé, en 1733. Por su parte, otro fray Domingos de São Tomé, que también declaró en 1733, vivía en el convento de religiosas domincas irlandesas. ANTT, TSO, CG, Habilitações, mç. 1, doc. 16 (Patrício de São Tomé); mç. 2, doc. 69 (Pedro da Encarnação); mç. 50, doc. 821 (Domingos Daly); mç. 1, doc. 1 (Hugo Maguire).

56 Se trata de fray Domingos de São Tomé, que declaró en 1733 en la prueba de limpieza de sangre de Hugo Maguire. Sobre el monasterio del Bom Sucesso, vid. SANTA CaTarina, Fr. Lucas de, História de S. Domingos, Cuarta Parte, págs. 1182 y ss. 
vincia de Bretaña, como base para las misiones en Ultramar ${ }^{57}$. Por ello, no es casualidad que los tres franceses que ingresaron en el Santo Oficio como calificadores entre 1676 y 1703 perteneciesen a la orden de los franciscanos capuchinos, procediesen de Bretaña y viviesen en este convento de la Porciúncula. Además, al igual que ocurrió con los irlandeses, en sus pruebas de limpieza de sangre declararon como testigos, principalmente, otros capuchinos bretones del mismo convento ${ }^{58}$.

Aunque, como decimos, la mayor parte de las pruebas de limpieza tuvieron lugar en Lisboa, hubo tres casos, todos de irlandeses, en los que los interrogatorios se realizaron fuera de la capital. Fray Francisco Marim, irlandés, vivía en el convento de San Francisco de Evora, donde era profesor de Teología. Los interrogatorios se hicieron en esta ciudad y en ellos declararon tanto irlandeses, para probar su limpieza de sangre, como teólogos, para averiguar su capacidad para desempeñar el oficio de calificador ${ }^{59}$. Por su parte, las informaciones sobre Gabriel Talbott y João Currim se realizaron en Oporto, en 1731 y 1765, respectivamente. Gracias a ellas podemos saber que, en el siglo XVIII, en Oporto existía una notable comunidad irlandesa, casi toda radicada en la parroquia de San Nicolás e integrada, en su mayoría, por hombres de negocios ${ }^{60}$.

57 Almeida, Fortunato de, História da Igreja em Portugal, vol. II, Lisboa-Porto, Livraria Civilização, 1968, pág. 188.

58 Capuchinos franceses residentes en el convento de la Porciúncula de Lisboa eran: Fr. Hilarião de Saint-Malo, Fr. Cláudio de Vitre y Fr. Paulino de Renaz, que declararon como testigos en 1676; Fr. Aleixo de Dinam, Fr. Constantino de Nantes, Fr. Paulino de Rennes, Fr. Pacífico de Rennes y Fr. Henrique de Chateaubriant, en 1695; Fr. Aleixo de S. Francisco, Fr. Inácio de Quimper, Fr. Plácido de Lannion, Fr. Henrique de Châteaubriant, en 1703. En 1676, en la habilitación de fray Constantino de Nantes, declararon, además de los capuchinos, otros dos franceses: Bertrand Colonel, mercader, y Ferdinand de La Guérinière, que vivía de su hacienda. ANTT, TSO, CG, Habilitações, mç. 2, doc. 20 (Constantino de Nantes); mç. 1, doc. 16 (Aleixo Josselin); mç. 121, doc. 1815 (Francisco de Pontable).

59 Irlandeses eran el sargento mayor João Hogan y los padres Tomás Tabin, Diogo Daly y Guilherme Russell. Por su parte, los profesores de Teología eran fray Manuel do Horto, OFM; Fr. Bernardino de São Bento, OFM; fray José do Espíritu Santo, OSA; fray Custódio do Rosário, OP, y fray Domingos de Amorim, OP. ANTT, TSO, CG, Habilitações, mç. 121, doc. 1819 (Francisco Marim).

${ }^{60}$ En 1731, declaron en las informaciones extrajudicial y judicial sobre Gabriel Talbott los siguientes irlandeses residentes en Oporto: Pedro Arcediago, hombre de negocios; Diogo Archer, hombre de negocios; Ricardo Juane; Nicolau Martin, hombre de negocios; João Commefort, hombre de negocios; el doctor João Baptista Tolle; Paulo Bronock; Diogo White, hombre de negocios; Margarida Aycroard; Maria Pausson; Margarida Rita; Alicia Archriago; Pedro Jack y su mujer; João Hughes, su mujer e hija; Marcos Bodden; Jorge Commefort, hombre de negocios; Marcos Rodkin, hombre de negocios; Ricardo Vid, hombre de negocios; el doctor Pedro Brown; Tomas Reilly; Daniel McGrath, hombre de negocios, y Daniel MacGraw, sastre. En 1764, en las informaciones extrajudicial y judicial sobre el padre João Currim, declararon los siguientes irlandeses también residentes en Oporto: el padre João Busler, de la congregación de San Felipe Neri; fray Francisco Reilly, OFM; Henrique Verna, hombre de negocios; fray Henrique Dillon, OSA; el doctor Simão Goold, médico; Carlos McCarthy, sargento mayor del regimiento de 
Mayores problemas planteaba comprobar la limpieza de sangre del padre Federico Retz, teatino natural de Dinamarca, debido a la escasez de católicos daneses que pudieran declarar ante el Santo Oficio. De hecho, la Inquisición solo pudo contar con el testimonio del propio cónsul de Dinamarca en Lisboa que, curiosamente, era católico. De modo que en la prueba de limpieza de Retz testificaron cuatro religiosos teatinos, que — claro está - no conocían a su familia. Por ello, el inquisidor general tuvo que dispensar la falta de noticias sobre sus antepasados ${ }^{61}$.

Antes de concluir este apartado, debemos preguntarnos hasta qué punto era útil recurrir a testigos naturales de los mismos reinos o provincias que los pretendientes a ingresar en el Santo Oficio. Es decir, cabe la duda de que, ante la imposibilidad de contar con informantes de las mismas ciudades que los habilitandos, los declarantes extranjeros no proporcionasen mayor información que la que hubiera podido prestar un portugués. Veamos, por ejemplo, el caso de los tres franceses que ejercieron de calificadores del Santo Oficio. En sus pruebas de limpieza de sangre, el Santo Oficio no se limitó a preguntar a testigos galos, sino que llamó, en todos los casos, a personas procedentes de Bretaña, de donde eran los habilitandos. Pero, mientras que quienes declararon en la prueba de Constantino de Nantes, en 1676, conocían o, al menos, tenían noticia de sus padres, abuelos o tíos, en la habilitación de Aleixo Josselin ningún informante había conocido ni a sus padres ni a sus abuelos. En algunos casos, los testigos coterráneos del pretendiente lo habían conocido ya en Portugal y, por ello, declaraban lo que habían oído decir a otros. Así, por ejemplo, todas las personas que testificaron en la prueba de limpieza de Gabriel Talbott eran irlandeses pero le habían conocido ya en Portugal.

En algunos casos, cuando el Santo Oficio no conseguía encontrar a ningún testigo que informase sobre la familia del pretendiente, el inquisidor general podía dispensar esta falta. Así hizo, en 1700, fray João de Lencastre para que Federico Retz pudiese ingresar en el Santo Oficio. Y en 1713, el diputado del Conselho Geral que estudió la prueba de limpieza de sangre de Alexandre Perié,

Braganza; Tomás Delany, maestro de lengua griega; Roque Arcediago, hombre de negocios; Nicolau Martin, hombre de negocios; Diogo Archbold, hombre de negocios; Leonor Delany; Maria Molloy, mujer del tendero Duarte Molloy; Margaret Casey, viuda del zapatero Bartolomeu Casey; Lucy Mitchell, mujer del capitán Isaac Milchel, y Brigit O'Dwyer, viuda del hombre de negocios Diego O'Dwyer. Como podemos ver, la comunidad irlandesa de Oporto era, en el segundo tercio del siglo XVIII, bastante numerosa y en ella destacaban, sobre todo, los hombres de negocios. Por el contrario, cien años antes, no había, que se sepa, ningún comerciante irlandés establecido en Oporto. Silva, Francisco Ribeiro da, O Porto e o seu termo (1580-1640). Os homens, as instituições e o poder, Porto, Arquivo Histórico - Câmara Municipal do Porto, 1988, vol. I, págs. 337-338. ANTT, TSO, CG, Habilitações, mç. 3, doc. 25, fols. 4r-4v y 12r-29v (Gabriel Talbott); mç. 129, doc. 2002, fls. 4r-5v y 30r-53r (João Currim).

61 El padre Federico Retz y los teatinos que declararon en su prueba de limpieza de sangre vivían todos en la casa de Nossa Senhora da Divina Providência, la única que poseían los Clérigos Regulares en Portugal. ANTT, TSO, CG, Habilitações, maço 1, doc. 1 (Federico Retz). 
natural de Turín y morador en el colegio de los jesuitas de Bahía, no se olvió de señalar que «não consta de quem he filho e neto; nem as testemunhas são de sua pátria onde se não fés diligência», por lo que fue necesario una dispensa del cardenal da Cunha, inquisidor general ${ }^{62}$.

En las habilitaciones de los extranjeros no peninsulares encontramos algunos argumentos utilizados de forma recurrente por los testigos para probar la limpieza de los pretendientes. Por ejemplo, los irlandeses afirmaban frecuentemente que en su país no había judíos y que ninguna familia irlandesa toleraría mezclarse con herejes anglicanos ${ }^{63}$. El caso de los capuchinos franceses resulta especialmente interesante porque, según decían, antes de entrar en su orden habían pasado una prueba de limpieza para demostrar que no tenían antepasados herejes. De hecho, este era, mucho más que la cuestión de la sangre judía, el aspecto capital de las pruebas realizadas a los extranjeros. Así, por ejemplo, a finales del siglo XVII, en la habilitación de fray Aleixo Josselin, uno de los testigos, el también capuchino fray Pacífico de Nantes, declaró que en su orden había una constitución que prohibía admitir a personas cuyos padres y abuelos hubieran sido herejes ${ }^{64}$. Y el mismo fray Aleixo, cuando solicitó ingresar en el Santo Oficio, presentó tres certificados para probar su nobleza y limpieza de sangre. Se trataba de una fe de la corporación municipal, otra del párroco de la iglesia mayor de su ciudad y una última del prior del convento de capuchinos de Josselin, en Bretaña. En este último documento, el prior del convento aseguraba que, antes de ingresar en la orden, se habían realizado informaciones sobre fray Aleixo y por ellas había quedado demostrado que «seus pays e maiores forão dos nobres cidadões della sem se desviarem da fee católica» ${ }^{65}$.

Cuando el pretendiente ya había servido en otro tribunal inquisitorial - ya fuera la Inquisición española, ya la romana- el Santo Oficio portugués aceptaba su limpieza de sangre y se limitaba a comprobar su identidad. Así ocurrió en el caso de Carlos António Casnedi, que era calificador del tribunal de Tole-

62 ANTT, TSO, CG, Habilitações, mç. 2, doc. 23 (Alexandre Perie). En la habilitación declararon solo cuatro testigos, todos ellos portugueses y miembros de la Compañía de Jesús, que habían conocido al padre Alexandre Perié en el colegio de Bahía.

63 Así, fray Patrício de São Paulo declaró que los padres y abuelos de fray Patrício de São Tomé «sempre forão católicos romanos sem do contrario haver fama ou rumor e se a houvera ainda de cem annos a esta parte havia elle testemunha de ter noticia por quanto são notados de infamia entre os católicos aquelles que tiverão algum avó herege». ANTT, TSO, CG, Habilitações, mç. 1, doc. 16 (Patrício de São Tomé).

64 En las constituciones de los Frailes Menores Capuchinos de 1643 se ordenaba «que viniendo alguno a pedir el Abito, los Padres Ministros Provinciales diligentemente se informen de su naturaleza, calidades, y costumbres [...] Que sean Católicos, y firmemente crean todo aquello que cree, y tiene la Santa Romana Iglesia. Y quien huviere sido herege, ò infiel, no sea recibido». Constituciones de los Frailes Menores Capuchinos de San Francisco, aprobadas y confirmadas por nuestro muy Santo Padre el Papa Urbano VIII traducidas de lengua italiana en castellano, Madrid, Carlos Sánchez, 1944, pág. 4.

${ }^{65}$ ANTT, TSO, CG, Habilitações, mç. 1, doc. 16, fols. 4r-4v (Aleixo Josselin). 
do. Cuando este solicitó ingresar en el tribunal portugués, el Conselho Geral no realizó pruebas de limpieza porque dio por buenas las que se habían hecho en España y se dedicó, simplemente, a comprobar la identidad del pretendiente. Este hecho resulta especialmente interesante si tenemos en cuenta que la Inquisición no aceptaba las habilitaciones realizadas por otras instituciones lusas.

Sin lugar a dudas, el caso más espectacular de un extrajero que formó parte del Santo Oficio portugués es el de Francisco André. Este mercader francés era natural de Aviñón, ciudad que pertenecía a los Estados Pontificios. Allí había ingresado en la cofradía de los Crucesignati en 1645. Más tarde, se trasladó a vivir a Lisboa, donde casó con una portuguesa. Una vez aquí, André pidió al inquisidor general don Francisco de Castro que le concediese carta de familiar del Santo Oficio portugués, pues ya lo era de la Inquisición papal ${ }^{66}$. El francés presentó al Conselho Geral su provisión, firmada por el dominico que ejercía de inquisidor en la ciudad de Avión. El Santo Oficio portugués consideró válida la provisión del inquisidor dominico. Por ello, el tribunal de Lisboa se limitó a preguntar testigos que confirmasen no la limpieza de sangre sino la propia identidad de Francisco André. Se trataba, únicamente, de averiguar si él era el mismo que aparecía en la carta de crucesegnatio7.

\section{CONCLUSIÓN}

En 1655, un tal Etienne Farin, mercader francés que vivía en Oporto, presentó una curiosa petición al Santo Oficio. Deseaba que el tribunal lo nombrase traductor o língua de las visitas a los navíos franceses que llegaban a la ciudad del Duero. Pero como el comisario encargado por el Santo Oficio de llevar a cabo su prueba de limpieza de sangre no encontró ningún francés que pudiese declarar sobre el pretendiente y su familia, Etienne Farin propuso que la Inquisición se informase en el propio París y se comprometió a sufragar los gastos que tan costosa diligencia pudiese ocasionar ${ }^{68}$. El deseo de este francés de ingresar en el Tribunal de la Fe fue compartido por muchos otros extranjeros durante los tres siglos de existencia de la institución. Integrar el Santo Oficio proporcionaba ventajas fiscales y procesales pero en Portugal servía, sobre todo, para demostrar públicamente la limpieza de sangre y, conforme avanzó el siglo XVII y durante el XVIII, el ascenso social. Además, en el caso de los extranje-

66 «por o treslado authentico da provisão que offerece foi criado familiar do Sancto Officio da dita cidade d'Avinhão, e porque quer usar tambem do ditto officio nesta cidade e ser admetido ao numero dos familiares della». TSO, CG, Habilitações, mç. 7, doc. 290 (Francisco André). ANTT, TSO, IL, liv. 105, fol. 97v.

67 Al mismo tiempo, el tribunal realizó las pruebas de limpieza de sangre de la mujer de André, que era portuguesa.

68 Evidentemente, el Conselho Geral no aceptó este arbitrio. ANTT, TSO, Habilitações, mç. 1, doc. 18 (Estévão Farim). 
ros, permitía consolidar su proceso de integración en la sociedad portuguesa. De ahí que en el siglo XVIII tantos comerciantes y hombres de negocios gallegos asentados en Portugal deseasen conseguir la carta de familiares de la Inquisición. Por su parte, el Santo Oficio supo valerse de los conocimientos y, sobre todo, del dominio de diferentes idiomas de religiosos italianos, franceses e irlandeses y se sirvió de ellos como calificadores de proposiciones, censores de libros y confesores de reos extranjeros.

En un principio, la cuestión de la naturaleza de los ministros, oficiales y familiares de la Inquisición portuguesa no planteó problema alguno. El inquisidor general don Henrique recurrió a eclesiásticos que habían integrado el Santo Oficio español y en los Regimentos de 1554 y de 1570 nada se establecía sobre este aspecto. Durante la Unión Dinástica, la comparación entre el Santo Oficio portugués y el español y entre sus modos de proceder fue un aspecto constante. Pero, quizás por ello, se fue imponiendo cada vez más la obligación de la naturaleza para desempeñar un oficio o ministerio en el tribunal portugués, precisamente al mismo tiempo que se debatían en la corte distintos arbitrios para introducir eclesiásticos de las coronas de Castilla y Aragón en la Inquisición lusa. Este proceso concluyó en el Regimento de 1640, la única de todas las instrucciones de la Inquisición portuguesa en la que se establecía el ser portugués como condición para ingresar en el tribunal. De hecho, en el Regimento de 1774 desapareció este requisito. Esta especificidad del Regimento de 1640 se debe a que lo que antes de 1580 era una cuestión meramente eclesiástica a partir de 1580 adquirió unas connotaciones políticas que desaparecieron a finales del siglo XVII, después de la Guerra de Restauración.

Recibido: 10-01-2011

Aceptado: 18-04-2011 